\title{
Development and evaluation of in situ novel intragastric controlled-release formulation of hydrochlorothiazide
}

\author{
RAVIKUMAR R. PATEL ${ }^{1 *}$ \\ JAYVADAN K. PATEL ${ }^{2}$ \\ 1 Jodhpur National University \\ Jodhpur, Rajshathan, India \\ 2 Department of Pharmaceutical \\ Technology, Nootan Pharmacy \\ College, Visnagar-384315 (GUJ) \\ India
}

Accepted December 15, 2010

\begin{abstract}
In situ forming intragastric controlled-release formulation is a new technology in the field of oral controlled-release delivery systems. The objective of this study was to develop formulations that can control drug release up to 24 hours. In addition, a combination of appropriate polymers and solvents was selected that could form a drug loaded gel at the process temperature of $60-70{ }^{\circ} \mathrm{C}$, which gel could turn into a rigid mass upon exposure to dissolution fluid at body temperature. The drug release mechanism from this rigid mass was controlled by different formulation factors such as different polymer grades, polymer concentrations, hydrophobicity or hydrophilicity of solvents, different drug loadings, and physicochemical properties of additional excipients. After evaluating different formulation factors, Ethocel $10 \mathrm{FP}$ and triethyl citrate were selected for further studies using hydrochlorothiazide as a model drug. Polynomial correlation between viscosity of the blank gel and drug release profile was also obtained.
\end{abstract}

Keywords: physical compatibility, hydrochlorothiazide, polymer grade, drug loaded gel, polymer concentration viscosity

Formulation development involves various systematic approaches to ensure safety, efficacy and stability of the final dosage form. Every formulation scientist would prefer to encounter stability issues during the early stages of formulation development. Therefore, a well-designed compatibility study is an important step during the early stages of formulation development.

In situ forming intragastric formulations (ISFIF) are liquid or semisolid formulations, which are filled in hard or soft gelatin capsules. Gelatin capsules are sensitive to moisture, temperature and residual impurities present in other excipients and the pharmaceutically active ingredient. Moisture exchange rate between the gelatin shell and excipients plays a critical role in gelatin shell stability. The optimum water content for liquid

\footnotetext{
*Correspondence; e-mail: raviptl_84@yahoo.co.in
} 
filled masses is necessary analysis, while the physicomechanical and physicochemical properties of gelatin in the presence of heat, water and stress (1-3). Gelatin capsules are not compatible with excipients containing an aldehyde group, reducing sugars, ascorbic acids, peroxides, etc. $(4,5)$. Therefore, a compatibility study of gelatin capsules and excipients used to formulate the ISFIFs is critical during the formulation development process.

After selecting the excipients compatible with the hard gelatin shell, subsequent steps are to select suitable materials that can form ISFIFs and to study the different formulation factors affecting drug release from the ISFIFs. Physicochemical properties of different polymers and the interactions polymer-solvent, polymer-water, and solvent-water play a critical role in forming the rigid mass. The mechanism of drug release from this rigid mass is controlled by different formulation factors such as polymer type, grade, and concentration, hydrophobicity or hydrophilicity of solvent, different drug loadings, physicochemical properties of the drug, and physicochemical properties of additional excipients added to the formulation (6).

Therefore, the objectives of this study were to: perform a preliminary study to ascertain the physical compatibility of different solvents with hard gelatin capsules, and to screen out highly incompatible solvents; select a combination of an appropriate polymer and solvents that can formulate in situ forming intragastric controlled-release formulations; investigate different formulation variables affecting the release of hydrochlorothiazide from the in situ forming intragastric controlled-release formulations (ISFIFs); and elucidate the mechanism of drug release from these controlled release formulations through water penetration studies.

\section{EXPERIMENTAL}

\section{Materials}

Different controlled-release hydrophobic polymers, namely, Ethocel (Ethocel Standard FP Premium grade with Ethoxyl content of 48-49.5 \%, Dow Chemical Company, USA), Eudragit RS PO (Degussa Rohm Pharma Polymers, USA), Carbopol 971P (Noveon, USA), cellulose acetate (Astron Ltd, India), and Kollidon SR (BASF Corporation, USA) were used in the study. Three different grades of ethyl cellulose were used. They were Ethocel $7 \mathrm{FP}$ with particle size of $9 \mu \mathrm{m}$, Ethocel $10 \mathrm{FP}$ with particle size of $6 \mu \mathrm{m}$, and Ethocel 100 FP with particle size of $48 \mu \mathrm{m}$.

Eight different solvents, namely, triethyl citrate (TEC), acetyltriethyl citrate (ATEC), tributyl citrate (TBC), acetyltributyl citrate (ATBC), diethyl phthalate, ethyl benzoate, benzyl alcohol and polyethylene glycol (PEG), were purchased from Astron Ltd, India. Sodium bromide was used to prepare the stability chamber with $65 \%$ RH. Hard gelatin capsules were obtained from (Capsugel Peapack, USA) and was a gift of Torrent research center India. Hydrochlorothiazide was used as a model drug.

\section{Methods}

Compatibility study. - Hard gelatin capsules, size 00, were filled with different solvents. Filled and sealed capsules were carefully put into scintillation vials and stored 
under the following different conditions: process temperature of $60{ }^{\circ} \mathrm{C}$ in an oven for 1 hour, room temperature, $25^{\circ} \mathrm{C} / 60 \% \mathrm{RH}$, in a desiccator with saturated sodium bromide solution for one month, and accelerated condition, $40{ }^{\circ} \mathrm{C}$, in an oven for one month. Visual inspections of filled and sealed capsules were conducted periodically to check for any physical damage, discoloration, and/or sweating of capsules.

Selection of polymers and solvents. - Preliminary screening was performed by mixing different types and grades of controlled-release polymers with two different solvents such as TEC and ATEC at 60 to $70{ }^{\circ} \mathrm{C}$ to see if the combinations of polymers and solvents would form blank gels. Initial formulations were prepared with two different types of controlled-release polymers, namely, Ethocel and Eudragit RS PO. Three different solvents, TEC, ATEC and TBC, were used. Appropriate amounts of the polymer and solvent were mixed and heated up to $70{ }^{\circ} \mathrm{C}$ with stirring. The polymer was dissolved in the solvent and formed a blank gel. Hydrochlorothiazide was added to the blank gel with continuous stirring. The resultant solid dispersion was poured into a hard gelatin capsule (7). The formulation that dissipated inside the dissolution medium was considered $a$ "failure" and the formulation that formed a solid mass inside the dissolution medium was considered "passed $«$.

Determination of drug release from gels. - Drug release from selected formulations was evaluated in triplicate using the USP Apparatus II at $50 \mathrm{rpm}(8-10) . \mathrm{HCl}\left(0.1 \mathrm{~mol} \mathrm{~L}^{-1}\right.$, $900 \mathrm{~mL}$ ) at $37 \pm 0.5^{\circ} \mathrm{C}$ was used as the dissolution medium. Hydrochlorothiazide concentration in the withdrawn samples was determined using a double beam UV-spectrophotometer (Shimadzu, Japan) at $271 \mathrm{~nm}$. The cumulative percentages of hydrochlorothiazide dissolved over time were calculated and plotted.

Different formulation factors. - In situ forming intragastric controlled-release formulations were prepared with five different concentrations of three different grades of a controlled-release polymer, namely, ethylcellulose (Ethocel 7 FP, 10 FP and 100 FP), and two different solvents, TEC and ATEC. A total of 30 different formulations were prepared using a full factorial $(3 \times 2 \times 5)$ design (Table I).

Viscosity. - Viscosity of blank gels was measured at $37{ }^{\circ} \mathrm{C}$ (body temperature) and $10 \mathrm{rpm}$ paddle speed (10), using a Brookfield 2.5 HBDV III cone and cup viscometer (Brookfield Engineering Company, Inc., USA) (11). The data was fitted in different mathematical models, i.e. Bingham Plastic, Casson, IPC (Interconnecting and Packging Electronic Circuits) paste and power law to see which model was the best fit for the data.

Based on the confidence of fit values, the IPC paste model was selected as the best-fit model. The IPC paste model is a commonly used model for measuring the viscosity of solder in electronics and plumbing industry. The IPC paste equation is as shown below:

$$
\eta=k R n
$$

where $\eta$ stands for viscosity (Pa s), $k$ is a consistency multiplier, $R$ is rotational speed in $\mathrm{rpm}$, and $n$ is a shear sensitivity factor. The paste equation is used to calculate the model parameters, namely, the shear sensitivity factor and gel viscosity $(\eta)$. 
Drug dissolution profile similarity. - Similarity between drug dissolution profiles was compared using $f 2$, values. The similarity factor, $f 2$, determines the closeness of two dissolution profiles using following equation (12):

$$
f_{2}=50 \times \log \left\{\left[1+(1 / n) \sum_{t=1}^{n}\left(R_{t}-T_{t}\right)^{2}\right]^{-0.5} \times 100\right\}
$$

where $f 2$ is the similarity factor, $R_{\mathrm{t}}$ is the cumulative percentage dissolved at each of the selected time points $(n)$ of the reference product, and $T_{\mathrm{t}}$ is the cumulative percentage dissolved at each of the selected time points of the test product. Two identical profiles have the $f 2$ value of 100 . If there is a $10 \%$ difference between two dissolution profiles, then the $f 2$ value is 50. According to the FDA guidelines (13), values between 50 and 100 show similarities between two profiles, thus indicating that there is less than $10 \%$ difference between the two dissolution profiles.

\section{RESULTS AND DISCUSSION}

\section{Compatibility study}

Benzyl alcohol, PEG 400 and ethyl benzoate were incompatible with the hard gelatin capsules. These solvents were either deforming the capsule shell or leaking within 24 hours at room temperature. All the remaining solvents (TEC, ATEC, TBC and ATBC) showed compatibility with the hard gelatin capsule at the process temperature of $60{ }^{\circ} \mathrm{C}$. Ethyl benzoate was sweating from the capsules at room temperature, $25^{\circ} \mathrm{C} / 60 \% \mathrm{RH}$. The possible reasons for these observations are as follows: the solvents changed the moisture content of the gelatin capsules and/or hydrophilic solvents partially dissolved the gelatin shell, resulting in leaking and/or sweating. PEG 400 filled in a hard gelatin capsule changed color under the accelerated condition of $40{ }^{\circ} \mathrm{C}$. This was due to the fact that PEG 400 degrades to peroxides and formaldehyde (14).

\section{Selection of polymers and solvents}

Preliminary screening studies showed that Ethocel, Eudragit RS PO and cellulose acetate butyrate formed gels with TEC and ATEC, but Carbopol, cellulose acetate and Kollidon SR did not. Hence, Ethocel and Eudragit RS PO were selected for further studies.

The initial formulations prepared with Ethocel 10FP and TEC formed solid masses that did not dissipate inside the dissolution media. However, the formulations prepared with Ethocel 10FP and TBC did not form solid masses and hence dissipated and accelerated the drug release from the gel by dumping the drug inside the dissolution medium. This phenomenon can be explained as follows. The solubility of TEC in water is $5.5 \mathrm{~g}$ per $100 \mathrm{~mL}$ while the solubility of TBC in water is less than $0.1 \mathrm{~g}$ per $100 \mathrm{~mL}$. Therefore, the hydrophilic solvent (TEC) leached out faster from the formulation than the hydrophobic solvent (TBC), causing the polymers to precipitate and form a hard shell or a rigid mass. This hard shell controlled the drug release. 
R. R. Patel and J. K. Patel: Development and evaluation of in situ novel intragastric controlled-release formulation of hydrochlorothiazide, Acta Pharm. 61 (2011) 73-82.

Formation of a solid mass was related to the type of polymer. Eudragit RS PO is a swellable, water insoluble polymer. Therefore, formulations prepared with Eudragit RS PO gelled and formed a loose swollen polymer structure (instead of forming rigid mass) in the dissolution media. This loose swelled polymer dissipated and hence dumped the

Table I. Composition of formulations used to prepare the drug-loaded gels ${ }^{a}$

\begin{tabular}{|c|c|c|c|c|}
\hline Batch No. & Polymer & Solvent & $\begin{array}{c}\text { Polymer/solvent } \\
\text { mass ratio }\end{array}$ & $\begin{array}{l}\text { Drug dissolution } \\
\text { result }\end{array}$ \\
\hline EC01 & Ethocel 10FP & TEC & $5: 95$ & Failed $^{\mathrm{b}}$ \\
\hline $\mathrm{EC} 02$ & & TEC & $10: 90$ & Passed \\
\hline $\mathrm{EC} 03$ & & TEC & $15: 85$ & Passed \\
\hline EC04 & & TEC & $20: 80$ & Passed \\
\hline EC05 & & TEC & $25: 75$ & Failed $^{c}$ \\
\hline EC06 & & ATEC & $5: 95$ & Failed $^{\mathrm{b}}$ \\
\hline EC07 & & ATEC & $10: 90$ & Passed \\
\hline EC08 & & ATEC & $15: 85$ & Passed \\
\hline EC09 & & ATEC & $20: 80$ & Passed \\
\hline EC10 & & ATEC & $25: 75$ & Failed $^{c}$ \\
\hline EC11 & Ethocel 7FP & TEC & $5: 95$ & Failed $^{b}$ \\
\hline EC12 & & TEC & 10:90 & Failed $^{\mathrm{b}}$ \\
\hline EC13 & & TEC & $15: 85$ & Passed \\
\hline EC14 & & TEC & $20: 80$ & Passed \\
\hline EC15 & & TEC & $25: 75$ & Passed \\
\hline EC16 & & ATEC & 5:95 & Failed $^{\mathrm{b}}$ \\
\hline EC17 & & ATEC & $10: 90$ & Failed $^{\mathrm{b}}$ \\
\hline EC18 & & ATEC & $15: 85$ & Passed \\
\hline EC19 & & ATEC & $20: 80$ & Passed \\
\hline EC20 & & ATEC & $25: 75$ & Passed \\
\hline EC21 & Ethocel 100FP & TEC & $5: 95$ & Passed \\
\hline EC22 & & TEC & $10: 90$ & Passed \\
\hline $\mathrm{EC} 23$ & & TEC & $15: 85$ & Passed \\
\hline EC24 & & TEC & $20: 80$ & Failed $^{c}$ \\
\hline $\mathrm{EC} 25$ & & TEC & $25: 75$ & Failed $^{c}$ \\
\hline EC26 & & ATEC & $5: 95$ & Passed \\
\hline $\mathrm{EC} 27$ & & ATEC & $10: 90$ & Passed \\
\hline EC28 & & ATEC & $15: 85$ & Passed \\
\hline EC29 & & ATEC & $20: 80$ & Failed $^{c}$ \\
\hline EC30 & & ATEC & $25: 75$ & Failed $^{c}$ \\
\hline
\end{tabular}

a $10 \%(m / m)$ drug loading

b Gel was fluid, hence dissipated and dumped the drug into the dissolution media.

c Gel was too viscous and hence unable to be filled into capsules. 
R. R. Patel and J. K. Patel: Development and evaluation of in situ novel intragastric controlled-release formulation of hydrochlorothiazide, Acta Pharm. 61 (2011) 73-82.

drug inside the dissolution medium. Based on the results of preliminary compatibility studies and the initial formulation screening study, the controlled-release polymer Ethocel and solvents TEC and ATEC were selected for further studies.

\section{Different formulation factors and polymer concentrations}

Gel formulations prepared with $5 \%$ of Ethocel $7 \mathrm{FP}$ and Ethocel $10 \mathrm{FP}$, and $10 \%$ of Ethocel 7 FP were liquid, and hence dissipated in the dissolution medium (Table I). As a result, drug release from these formulations was rapid (data not shown). Gel formulations prepared with $25 \%$ Ethocel $10 \mathrm{FP}$, and $20 \%$ and $25 \%$ Ethocel 100 FP were too viscous to be filled into capsules. Therefore, the working ranges of different grades of Ethocel were found to be: 10 to $20 \%$ Ethocel $10 \mathrm{FP}, 15$ to $25 \%$ Ethocel $7 \mathrm{FP}$, and 5 to $15 \%$ Ethocel 100 FP (Table I).

The percentage of drug release was directly related to the concentration of the polymer used to prepare gel formulations. The drug release rate decreased significantly $(p<$ 0.05 ) as the concentration of Ethocel $10 \mathrm{FP}$ in the blank gel increased from 10 to $20 \%$ (Fig. 1a). As shown in Fig. 1a, the entire drug (100\%) was released from the formulation prepared with $10 \%$ polymer after 24 hours, whereas only 72 and $31 \%$ of the drug was released from formulations prepared with 15 and $20 \%$ polymer, respectively, in 24 hours. However, there was no difference between drug release profiles of formulations prepared with 20 and $25 \%$ Ethocel $7 \mathrm{FP}$ and ATEC, in which only $12 \%$ drug was released in 24 hours (Fig. 1b). Hence, when the polymer concentration increased to $20 \%$ Ethocel 7 FP and above, it considerably prevented penetration of the dissolution medium inside the solid mass. Therefore, only the drug present in the outer layers of the solid mass was released from this formulation in 24 hours. Similar results were obtained from formulations prepared with 10 and $15 \%$ of Ethocel 100 FP and ATEC, respectively (Fig. 1c).
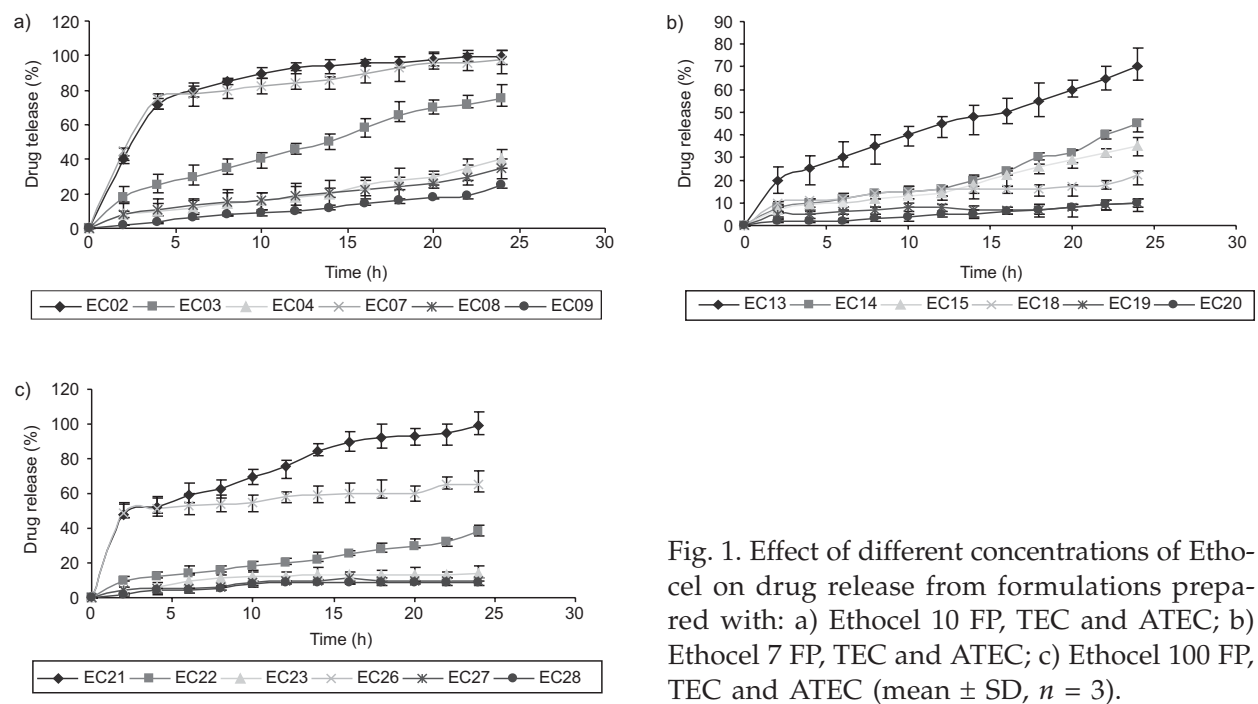

Fig. 1. Effect of different concentrations of Ethocel on drug release from formulations prepared with: a) Ethocel 10 FP, TEC and ATEC; b) Ethocel 7 FP, TEC and ATEC; c) Ethocel 100 FP, TEC and ATEC (mean $\pm \mathrm{SD}, n=3$ ). 
R. R. Patel and J. K. Patel: Development and evaluation of in situ novel intragastric controlled-release formulation of hydrochlorothiazide, Acta Pharm. 61 (2011) 73-82.

\section{Effect of viscosity}

The viscosity of blank gels increased as the Ethocel concentration in the formulation increased. There was a direct correlation between the polymer concentration and viscosity of blank gels, while there was an inverse correlation between the viscosity of the formulations and temperature. As the polymer concentration increased, the intermolecular interactions among ethylcellulose molecules and between ethylcellulose and solvent molecules increased, thus forming a strong rigid mass. Viscosity values were higher for the formulations prepared with ATEC compared to those prepared with TEC. Stronger interactions existed between ethylcellulose and ATEC molecules compared to ethylcellulose and TEC molecules as shown by measuring the glass transition temperatures $\left(T_{\mathrm{g}}\right)$ of blends of ethylcellulose and either TEC or ATEC. The $T_{\mathrm{g}}$ of ethylcellulose plasticized with ATEC was approximately $38-40{ }^{\circ} \mathrm{C}$, whereas the $T_{\mathrm{g}}$ of ethylcellulose plasticized with TEC was $32-34{ }^{\circ} \mathrm{C}$. The lower the $T_{\mathrm{g}}$ value, the stronger the interaction between the polymer and solvent.

The data of shear stress and rate of shear was best fitted in the IPC paste model. Table II shows the model parameters such as shear sensitivity, confidence of fit, drug release rates with their correlation coefficients and viscosity values at $10 \mathrm{rpm}$ for all the formulations at $37{ }^{\circ} \mathrm{C}$. Shear sensitivity of the gels increased from 0.06 to 0.21 as the polymer concentration increased from 10 to $20 \%$. Shear sensitivity was also higher with the formulations prepared with ATEC compared to those prepared with TEC.

Table II. Model parameters of gel formulations and drug release rates ${ }^{a}$

\begin{tabular}{ccccc}
\hline Batch No. & Viscosity (Pa s) & Shear sensitivity & Confidence of fit $(\%)$ & $R^{2}$ \\
\hline EC02 & 2.974 & 0.06 & 97.2 & 0.982 \\
EC03 & 11.347 & 0.13 & 98.1 & 0.993 \\
EC04 & 51.362 & 0.21 & 98.3 & 0.937 \\
EC07 & 5.793 & 0.17 & 98.1 & 0.972 \\
EC08 & 30.055 & 0.18 & 98.7 & 0.987 \\
EC09 & 11.317 & 0.44 & 94.6 & 0.992 \\
EC13 & 10.402 & 0.11 & 98.7 & 0.996 \\
EC14 & 38.970 & 0.18 & 99.0 & 0.958 \\
EC15 & 96.931 & 0.35 & 94.4 & 0.952 \\
EC18 & 23.058 & 0.28 & 97.5 & 0.920 \\
EC19 & 72.539 & 0.32 & 97.0 & 0.919 \\
EC20 & 186.442 & 0.53 & 93.3 & 0.972 \\
EC21 & 3.146 & 0.15 & 99.0 & 0.996 \\
EC22 & 38.162 & 0.23 & 98.1 & 0.976 \\
EC23 & 69.324 & 0.43 & 94.7 & 0.867 \\
EC26 & 4.314 & 0.23 & 95.2 & 0.869 \\
EC27 & 34.797 & 0.22 & 98.8 & 0.936 \\
EC28 & 61.568 & 0.89 & 72.8 & 0.979 \\
\hline
\end{tabular}

a $37^{\circ} \mathrm{C}$ 


\section{Effect of different types of solvents}

Solubility of plasticizers in the dissolution media affected the drug release as well. The drug release rate was slower from formulations containing ATEC compared to those containing TEC. For example, $30 \%$ of the drug was released in 24 hours from the formulation prepared with $15 \%$ Ethocel $10 \mathrm{FP}$ and $85 \%$ ATEC, whereas $85 \%$ of the drug was released from the formulation prepared with $15 \%$ Ethocel $10 \mathrm{FP}$ and $85 \%$ TEC within 24 hours (Fig. 2). Alternatively, the hydrophilic solvent, TEC, leached out faster from the formulation and created pores and channels through which water penetrated quickly inside the formulation and caused rapid drug release. However, the hydrophobic solvent, ATEC, leached out slowly from the formulation and did not form pores and channels for the drug to be released.

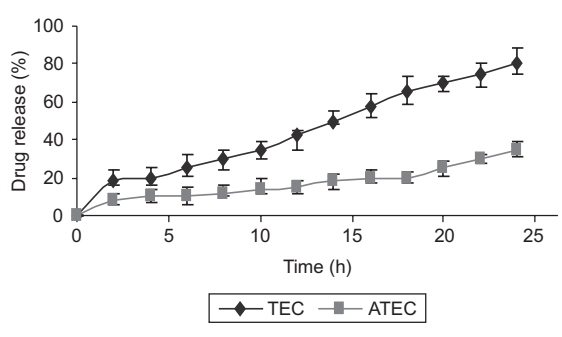

Fig. 2. Effect of different types of solvents on drug release from formulations containing Ethocel $10 \mathrm{FP}(15 \%, m / m)($ mean $\pm \mathrm{SD}, n=3)$.

\section{Effect of different polymer grades}

The drug release rate decreased as the viscosity grade of the polymer increased from 7 FP to 100 FP. Fig. 3. shows the drug release profiles related to different viscosity grades. There was no significant difference in drug release profiles of formulations prepared with Ethocel 7 FP and 10 FP grades with similar polymer concentrations. The $f 2$ value of dissolution profiles of formulations containing $15 \%$ Ethocel $7 \mathrm{FP}$ and $15 \%$ Ethocel $10 \mathrm{FP}$ was 64.04 . The slowest drug release rates were obtained with Ethocel 100 FP. Approximately $72 \%$ of the drug was released from the formulation containing $15 \%$ Ethocel $10 \mathrm{FP}$ and TEC, whereas only $14 \%$ of the drug was released from the formulation containing $15 \%$ Ethocel $100 \mathrm{FP}$ and TEC, within 24 hours. A polymer with a high viscosity grade has a higher number of monomers, and as a result has longer chains compared to

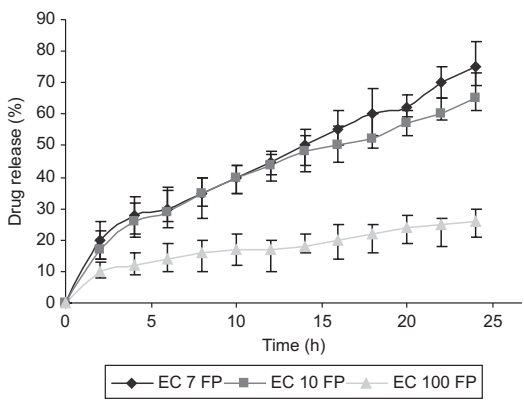

Fig. 3. Effect of different grades of Ethocel on drug release from formulations containing $15 \%$ $(\mathrm{m} / \mathrm{m})$ Ethocel of different grades and $85 \%$ $(m / m)$ TEC (mean $\pm \mathrm{SD}, n=3)$. 
those of a low viscosity grade polymer. As the viscosity grade increased from 0.01 (Ethocel $10 \mathrm{FP}$ ) to $0.1 \mathrm{~Pa} \mathrm{~s}$ (Ethcoel $100 \mathrm{FP}$ ), the number of monomers present in the polymer increased 10 times. Expectedly, the formulations prepared with higher viscosity ranges formed a stiffer mass with fewer pores and channels upon exposure to the dissolution medium, and thus retarded the drug release.

\section{CONCLUSIONS}

In situ forming novel intragastric controlled-release formulations could be prepared with different grades of ethylcellulose and different solvents such as TEC and ATEC. Hydrophobic solvents such as TBC and water swellable polymers like Eudragit RS PO may not be suitable for preparation of ISFIFs. As the Ethocel concentration in the formulations increased, the drug release rate decreased. Aqueous solubility of solvents affected the drug release as well. For example, formulations prepared with the hydrophilic solvent TEC (a solvent with an aqueous solubility of $5.5 \%$ ) showed faster drug release than those prepared with the hydrophobic solvent ATEC (a solvent with an aqueous solubility of $0.7 \%$ ). As the polymer molecular mass or viscosity grade of the polymer used to prepare ISFIFs increased, the drug release decreased. The higher the viscosity of the blank gel, the lower the drug release rate of the resultant formulation. Formulations with Ethocel 100 FP slowed slower drug release compared to formulations prepared with Ethocel 7 FP and Ethocel 10 FP. There was no significant difference in drug release characteristics between formulations prepared with Ethocel 7 FP and Ethocel 10 FP.

\section{REFERENCES}

1. M. Kuentz and D. Rothlisberger, Determination of the optimal amount of water in liquidfill masses for hard gelatin capsules by means of texture analysis and experimental design, Int. J. Pharm. 236 (2002) 145-152; DOI: 10.1016/S0378-5173(02)00022-4.

2. P. Kozlov and G. Burdygina, The structure and properties of solid gelatin and the principles of their modification, Polymer 24 (1983) 651-666; DOI: 10.1016/0032-3861(83)90001-0.

3. E. T. Cole, D. Cade and H. Benameur, Challenges and opportunities in the encapsulation of liquid and semi-solid formulations into capsules for oral administration, Adv. Drug Del. Rev. 60 (2008) 747-756; DOI: 10.1016/j.addr.2007.09.009.

4. G. Reich, Effect of sorbitol specification on structure and properties of soft gelatin capsules, Pharm. Ind. 58 (1996) 941-946.

5. S. Nagata, Advantages to HPMC capsules: A new generation's hard capsule, Drug Del. Technol. 2 (2002) 6-9.

6. S. K. Dordunoo, J. L. Ford and M. H. Rubinstein. Preformulation studies on solid dispersions containing triamterene or temazepam in polyethylene glycols or gelucire $44 / 14$ for liquid filling of hard gelatin capsules, Drug Dev. Ind. Pharm. 17 (1991) 1685-1713; DOI: 10.3109/03639049109057315.

7. W. J. Bowtle and N. J. Barker, A new approach to vancomycin formulation using filling technology for semisolid matrix capsules, Pharm. Tech. 12 (1988) 86-97.

8. Unated States Pharmacopoeia 28, National Formulary 23, USP Convention, Rockville (MD), Asian Edition, 2005. 
R. R. Patel and J. K. Patel: Development and evaluation of in situ novel intragastric controlled-release formulation of hydrochlorothiazide, Acta Pharm. 61 (2011) 73-82.

9. K. A. Shah, J. W. Warren, G. Onwuelezi, J. S. Benmaman and C. M. Monk, In vitro release of hydrochlorothiazide from capsule formulations, Drug Dev. Ind. Pharm. 7 (1981) 683-691; DOI: 10.3109/03639048109055692.

10. P. R. Petrovick, M. Jacob, D. Gaudy, V. Bassani and S. Guterres, Influence of adjuvants on the in vitro dissolution of hydrochlorothiazide from hard gelatin capsules, Int. J. Pharm. 76 (1991) 49-53; DOI: 10.1016/0378-5173(91)90342-L.

11. S. Miyazaki, N. Kawasaki, W. Kubo, K. Endo and D. Attwood, Comparison of in situ gelling formulations for the oral delivery of cimetidine, Int. J. Pharm. 220 (2001) 161-168; DOI: 10.1016/ S0378-5173(01)00669-X.

12. V. Shah, Y. Tsong, P. Sathe and J. Liu, In vitro dissolution profile comparison-statistics and analysis of the similarity factor f2, Pharm. Res. 15 (1998) 889-896; DOI: 10.1023/A:1011976615750.

13. U.S. Department of Health and Human Services, Food and Drug Administration Center for Drug Evaluation and Research, Guidance for Industry: Dissolution Testing of Immediate Release Solid Oral Dosage Forms, FDA CDER, Rockwille (MD) 1997; http:/ / www.fda.gov/downloads / Drugs / GuidanceComplianceRegulatoryInformation/Guidances/ucm070237; access date December 15, 2010.

14. N. Gatchalian, L. Joseph, C. Westergom and N. Langley, Purity of PEG 400 effects the stability of gelatin capsules, American Accociation of Pharmaceutical Scientists Annual Meeting, November 6-10, 2005, Book of Abstracts, AAPS, Nashville (TN) 2005, R6012.

\section{$S A \check{Z} E T A K$}

\section{Razvoj i vrednovanje novog ljekovitog pripravka hidroklortiazida za kontrolirano oslobađanje u želucu in situ}

RAVIKUMAR R. PATEL i JAYVADAN K. PATEL

In situ izrada pripravka za kontrolirano oslobađanje nova je tehnologija u području peroralnih sustava za kontrolirano oslobađanje ljekovite tvari. Cilj rada bio je razvoj pripravka za kontrolirano oslobađanje lijeka do 24 sata. Provedena su preliminarna ispitivanja fizikalne kompatibilnosti različitih otapala s tvrdom želatinskom kapsulom. Ispitane su različite kombinacije polimera i otapala kako bi se pronašle kombinacije koje mogu tvoriti gel s uklopljenom ljekovitom tvari pri temperaturi izrade od $60-70{ }^{\circ} \mathrm{C}$ koji prelazi u čvrstu strukturu nakon izlaganja tekućem mediju za oslobađanje pri tjelesnoj temperaturi. Mehanizam oslobađanja lijeka iz te čvrste strukture kontroliraju različiti faktori poput stupnja polimerizacije, koncentracije polimera, hidrofobnosti ili hidrofilnosti otapala, količine uklopljenog lijeka i fizičko-kemijskih svojstava dodanih pomoćnih tvari. Nakon evaluacije različitih formulacijskih faktora, za daljnja ispitivanja odabrani su Ethocel 10 FP i trietil-citrat. Kao model-lijek upotrijebljen je hidroklortiazid. Utvrđena je polinomska korelacija s viskoznošću gela bez ljekovite tvari. Određen je profil oslobađanja lijeka.

Ključne riječi: fizikalna kompatibilnost, hidroklortiazid, stupanj polimerizacije, gel s uklopljenim lijekom, koncentracija polimera, viskoznost

Department of Pharmaceutical Technology, Nootan Pharmacy College, Visnagar-384315 (GUJ), India 